\title{
Short-put exposures in hedge fund returns: Are they really there?*
}

\author{
André Lucas ${ }^{\ddagger \S}$, Arjen Siegmann ${ }^{\ddagger}$, and Marno Verbeek ${ }^{\llbracket}$
}

This version: May 2008

\begin{abstract}
Previous studies have shown that systematic risk in hedge fund returns is partly captured by short positions in put option returns. This is suggestive of a potential 'peso problem' in hedge fund returns: a series of steady returns may alternate with an occasional crash. In this paper, we analyze whether equity option-exposures are actually there, and find they are not. Although some hedge fund indices show some exposure to put or call-returns, several robustness analysis as well as an analysis of individual hedge fund returns show that exposures are not consistent with fundamental characteristics of options, such as put-call parity and the positive relation between option prices and volatility.
\end{abstract}

Keywords: hedge funds, nonlinear systematic risk factors, option factors, stability.

\section{Introduction}

Hedge funds are known to have dynamic and nonlinear exposures to returns on established indices, such as stocks and bonds. Fung and Hsieh (1997) are amongst the first to make

${ }^{*}$ We are grateful to Inquire Europe and Netspar for financial support. Correspondence to: asiegmann@feweb.vu.nl.

${ }_{\ddagger}^{\ddagger}$ Department of Finance, VU University Amsterdam, De Boelelaan 1105, NL-1081 HV Amsterdam, the Netherlands.

§Tinbergen Institute Amsterdam, Roetersstraat 31, NL-1018 WB, Amsterdam, the Netherlands.

IRSM Erasmus University and Netspar, P.O. Box 1738, 3000 DR Rotterdam, the Netherlands. 
this idea explicit. They show that the standard Sharpe (1992) factor model does not work well for hedge fund index-returns. Instead, quintiles of hedge fund returns display a non-linear relation with standard market factors such as the US-equity returns, the gold price, and the dollar exchange rate. Agarwal and Naik (2004) take this result a step further and actually estimate exposures of hedge fund index-returns to nonlinear factors over the period 1990-2000. They find that (S\&P 500) option-based factors have significant explanatory power. The inclusion of (short) option factors to explain hedge fund returns is suggestive of stable hedge fund returns that are plagued occasionally by sharp, negative returns. If such patterns are stable, we expect to find some strong signals around the 'slow-but-steady' crash of the stock markets after 2000. In this paper, we address the robustness of the above results paying attention to a more recent time span.

The finding that hedge funds tend to have negative loadings on put option factors may have several causes. First, hedge funds are known to follow highly dynamic investment strategies. They may move into and out of assets and asset classes repeatedly over time. A standard regression analysis for performance attribution using familiar asset class returns for stocks, bonds, commodities, and so on, may not capture such a dynamic strategy. Merton (1981) argues that trend followers (as an example of a dynamic strategy) have return patterns that mimic those of a long straddle. Based on these arguments, Fung and Hsieh $(2002,2004)$ introduce returns on (lookback) straddles on bond futures, currency futures, and commodity futures as additional risk factors in style regressions for hedge fund returns. Also Mitchell and Pulvino (2001) and Agarwal and Naik (2004) use option returns to capture the dynamic nature of particular hedge fund styles.

Second, writing put options results in an attractive pay-off pattern under traditional performance measures. Goetzmann et al. (2002) show analytically that a short put-like payoff is optimal if one tries to maximize the Sharpe ratio. Generating a high Sharpe ratio with a strategy that does not necessarily involve skill can be called 'informationless investing', a term coined by Weisman (2002). According to Weisman, the hedge fund 
industry is particularly vulnerable to adopting such strategies. In another context, Brown et al. (2005) find that Australian equity managers show patterns of trading that seem to be aimed at payoffs with a large downside risk but, nonetheless, an attractive Sharperatio. Siegmann and Lucas (2007) show that even if the Sharpe ratio is replaced by a downside risk measure, short put options remain attractive using statistical performance measures.

Third, the option returns might proxy for other systematic risk factors that are particularly of interest in the hedge fund context. The two prime examples that come to mind are (systematic) volatility risk and liquidity risk, see for example Chan et al. (2005).

Fourth, the finding of short put factors in hedge fund returns might be a spurious result. In particular, the turmoil in 1998 around the Russian default and the LTCM crisis might have created a simultaneous crash in hedge fund returns and option markets, without giving rise to a structural, systematic pattern.

The current paper addresses a number of important issues in this context. Our work is related to that of de los Rios and Garcia (2005), who consider a very general approach to assessing nonlinear factor exposures. Also Baquero and Verbeek (2005) use portfolio construction based on past performance to analyze whether hedge fund investors follow the best performing funds.

First, we extend the estimation and risk factor selection strategies of Agarwal and Naik (2004) over a more recent period. We find similar results as Agarwal and Naik, in that for some hedge fund indices, significant loadings to option returns are found. However, these loadings are not stable over the pre-bubble and post-bubble period. This questions the stability of style regression results for hedge funds. In addition, we find that the call option loadings do not correspond to the put loadings, although put-call parity suggests they should be. This is surprising, as especially the put option factors have attracted attention in the literature, Agarwal and Naik (2004), and enjoy some theoretical support; 
see Goetzmann et al. (2002). The call options are supposed to be in line with trend following strategies or market timing ability, see Merton (1981) and Fung and Hsieh (2002), but we do not find evidence for this either.

The rest of this paper proceeds as follows. Section 2 estimates the exposures of index returns to market- and option-based factors for the two subperiods. Section 3 considers portfolios of individual hedge funds constructed by sorting on fund characteristics. Section 5 concludes.

\section{Data}

The index data used in this paper are from TASS/Tremont and Hedge Fund Research (HFR). Both sets of indices are publicly available. The TASS/Tremont indices are valueweighted and have a minimum fund size of $\$ 50$ million. The HFR indices are equally weighted with no asset-size minimum. Both indices provide returns on different hedge fund styles, such as Emerging Markets, US equity, Dedicated Short bias, Managed Futures, Global Macro, and so on. These style attributes have been used in much of the remaining literature as well. The complete catalogue of styles used can be found in Table 1.

Table 1 also lists the market variables we use for the factor model estimation. SPX, MEM, MXUS, LHY, (L)RUS and FRBI are from Datastream, SBG, SBW and GSCI are from Bloomberg. DEF is the change in the default spread, where the spread is the difference between the yield on the BAA-rated corporate bonds and the 10-year Treasury constant maturity rate as provided by Federal Reserve Economic Data (FRED). SMB, HML, Rf are from Kenneth French's website where Rf is the 1-month Treasury bill rate provided by Ibbotson Associates. In addition, to compute the option-based risk factors we use as volatility the CBOE SPX volatility index (VIX). 
The returns on two option-based risk factors, SPP and SPC, are computed using BlackScholes prices and the empirical risk-free rate, S\&P 500 return (SPX) and the Chicago Board Options Exchange SPX Volatility Index for the volatility. At the beginning of the month, we compute the Black-Scholes price of the call and option contract, expiring in 7 weeks (third week of next month). At the end of the month, we compute new prices using the empirical implied volatility, riskfree rate and return on the S\&P. This method, which is also used by Agarwal and Naik (2004) for the period for which market option data were not available, provides us with 1-month option returns. We only use at-the-money options to avoid Black-Scholes pricing problems that are aggravated with out-of-the money options. Note that the out-of-the-money options used by Agarwal and Naik have strike prices that are only 1\% higher or lower than the ATM factors. Also, in contrast to Agarwal and Naik, we use the S\&P 500 index instead of the Russell 3000, to account for the fact that the SPX and SPP/SPC factors are related.

Table 2 provides the summary statistics of the hedge fund returns and the risk factors. If we look at the hedge fund return sample moments and the differences between the TASS and HFR data base, we see that some styles are fairly similar across data sets. For example, Convertible Arbitrage (CA) has similar moments for TASS and HFR. Other styles, however, may have substantially different higher order moments (e.g., Event Driven (ED)). This is also evident from a casual inspection of the minimum and maximum of the returns on the different hedge fund styles. These differences underline the importance of double checking the results in our analysis with the two databases. While we can do this at the index level, we only have the TASS data base at our disposal for the individual hedge fund returns.

The lower panel of Table 2 gives the sample summary statistics for the risk factors. Interestingly, there are substantial differences between the higher order moments of the 
risk factors and a number of the hedge fund returns. This signals that it may be hard to capture these moments in a standard style regression framework.

In the final part of the paper, we construct portfolios of hedge funds using the TASS/Tremont database on individual hedge funds. The data cover the period up to December 2004. This provides us with data of a total of 5126 funds, with 3178 live funds as of December 2004. We remove funds with less than 12 months of return history, funds that do not report in US-Dollar, as well as funds with too many missing values for asset size. One of the cross-sectional sorts we study uses estimated asset values. The data on estimated assets contain many missing values. With 3013 funds having one or more missing asset values, discarding these funds or just these observations is not an option. Instead, we interpolate asset values assuming a constant money-growth in assets during any consecutive period of one or more missing values. Missing values for asset values at the start or end of the fund history are discarded. For the US-equity focused funds this leaves us with 3008 funds of which 1720 are still alive as of December 2004.

\section{$3 \quad$ Factor model estimates of index-returns}

The basic claim of Agarwal and Naik (2004) is that a large number of equity-oriented hedge fund index-returns have a negative loading on the return on S\&P 500 put options. The methodology of Agarwal and Naik has an implicit model selection procedure to strip down the complete set of 20 initial risk factors to a smaller set. However, this makes the option factors incomparable across models as a result of the specification search. Thus, our estimates are concerned with factor models that use all market factors. Subsection 3.1 presents the results for the hedge fund indices from the HFR database, Subsection 3.2 for the TASS/CSFB indices. 


\section{$3.1 \quad$ HFR}

The results for HFR are in Table 3. The values for the adjusted $R^{2} \mathrm{~s}$ in the table confirm the notion that several of the index returns can be reasonably well explained by a factor model. Five styles (ED, ENH, EH, SS, EM) have an $R^{2}$ between 78 and $92 \%$. This seems to fly in the face of the earlier observations made by Fung and Hsieh (1997), who argue that the factor model approach of Sharpe (1992) for mutual funds does not work for hedge funds. They change the size and extent of exposures to different asset classes too quickly to be captured by a linear combination of market factors. Possibly, our results show that

hedge funds have taken up more systematic risk, as a result of the spectacular growth in assets under management, or, the index-returns from the HFR database cannot be seen as representative for the returns to hedge fund investing for a typical investor.

A few observations on the factor loadings from the table. First, large loadings on SPX are, as expected, found for ENH, EH and SS (negative). Second, only three styles (CA, FI and EM) do not load significantly on SMB. SMB represents the excess return of small stocks relative to large stocks. Thus, the size premium is an is an important driver of hedge fund returns. Third, a large loading on the MSCI Emerging Markets index is only found for the Emerging Markets hedge fund index. Fourth, a large loading on high-yield (LHY) is as expected for DS, as LHY represents the returns to investing in distressed firms. The emerging market hedge fund index loads positively on SBGC and negatively on SBW. This is either multicollinearity (no: correlation .55), or emerging markets hedge funds pocketing the risk premium between corporate and sovereign bonds. (SBGC represents world corporate and government, SBW just government). The competitiveness-weighted dollar index (FRBI) has only a significant impact on Global Macro returns. For all the talk, commodity returns only have a significant affect for 4 hedge fund indices, and quite small. The Short Selling index is clearly a special category of hedge funds, having short exposure to SPX and SMB (as expected), but a large and significant exposure to HML. 
Finally, the coefficient for SPP is negative for ED, RVA and MA. For Relative Value Arbitrage and Merger Arbitrage, this is as expected, see Mitchell and Pulvino (2001). A tentative conclusion could be that risk arbitrage strategies have a short put exposure, but for the other hedge fund indices, there is no evidence for a systematic put option-exposure.

Besides the loadings, we can conclude that the factor model outcome suggests that the Emerging Market (EM) hedge fund style has significantly higher alpha than the other styles. This might be caused by the omission of systematic factors, given our limited set of 12 and the widespread scale of possible investments in that category.

DS, ED, CA, RVA and FI also have a significantly positive alpha, while the other index returns have no significant constant term. That would imply that less than half of the hedge fund index-returns would add value for an investor who already has exposure to the (tradable equivalents of the) market factors.

\subsection{TASS/CSFB}

The TASS/CSFB estimation results are in Table 6. Again, we observe that several of the index returns are quite well explained by a factor model. This holds particularly for Distressed Securites (DS), Event Driven (ED), Emerging Markets (EM), Long-Short Equity (LSE), and Dedicated Short Bias (DSB). These styles all have an adjusted $R^{2}$ of $60 \%$ or more. Relative Arbitrage (RA) and Multi-strategy (MS) have $R^{2}$ values of $41 \%$ and $55 \%$, respectively, which is substantially lower. At the lowest end, we find adjusted $R^{2}$ s values of $22 \%$ for Convertible Arbitrage, $12 \%$ for Equity Market Neutral, $13 \%$ for Fixed Income, 24\% for Global Macro (GM), and 24\% for Managed Futures (MF). For managed futures, this might be caused by missing an apprioprate factor return, related to the futures market. For the market-neutral strategy, the low $R^{2}$ corresponds to the purpose of the strategy, which appears to work well. In all, the results suggest that a 
factor model works quite well in explaining the returns to hedge fund indices.

Before discussing the estimates, we should note that the strategy definitions are different per database, and previous research suggests that even for indices that exist in both database, the number of disjunct funds (in one database, not in the other), is large. Bearing in mind the limited extent of overlap, we still see a number of corresponding patterns. We discuss the factor estimates first, and then explicitly focus on robustness of the SPP exposures across the two databases.

First, only the short selling strategy has a significant exposure to SPX (albeit negative). The hedge funds in the TASS database seem to have little direct exposure to large US stocks. Second, the Fama-French factors are again important, with 4 fund loading on HML and 6 on SMB. The emerging markets hedge funds have an exposure to the emerging markets factor, naturally, and LHY is significant for 8 out of 12 indices. For emerging markets, we find again the long-short combination of SBGC and -SBW, as found for HFR. Also similar is the positive loading of Macro on FRBI. The change in default spread is insignificant everywhere, and GSCI exposure is only visible for 2 strategies, but small.

For the TASS indices, only Distressed Securities (DS) has a significant loading on the put option return, -0.62. Hedge funds that invest in distressed securities buy debt or equity positions into firms filing for reorganization or bankruptcy. Such strategies are mostly accompanied by fundamental research that enables the hedge fund manager to judge whether the market price of the distressed debt/equity securities is possibly too high. Given a position in such a security, in a bull market (SPX returns above $-\mathrm{x} \%$ ), the risk premium is pocketed and the hedge fund makes a profit on its (leveraged) bet. In a bear market (negative SPX returns), firms in restructuring have a particularly hard time, and the risk of complete bankruptcy materializes. With this explanation we can imagine how a factor model for the DS index leads to a negative loading for the SPX put option return. 
A specific criticism is valid for the interpretation of the risk factors. Although S\&P indexoption returns capture the return on a very specific dynamic investment strategy, it is clear that it cannot capture a broad range of dynamic strategies. This is why for example Fung and Hsieh (2002) use a number of straddle returns in their style regressions, relating to bond, FX, and commodity markets.

\subsection{Robustness over time}

To analyze the robustness of the short put option-loadings over time, Tables 4 and 5 give the factor model estimates for two different time periods. The results are for the HFR indices, which had three indices with a short put loading over the full period. Distressed securities has a negative loading in the pre-bubble period and zero thereafter. Market Timing has a positive loading pre-bubble and negative post-bubble. Merger arbitrage comes out consistently with a negative loading, both before and after the bubble. Based on these results, we should conclude that only merger arbitrage might be considered to have a consistent and significant exposure to the return on SPX put options.

\subsection{Put-call parity}

In a Black-Scholes world there is a one-to-one relation between the price of a stock, a risk-free bond, a call and a put option (put-call parity). Although this does not translate to a one-to-one relationship in terms of returns, see Coval and Shumway (2001), the series are still closely related. As shown in Figure 1, the difference between the call and the put

return has an almost linear relationship with the underlying index (SPX), with an $R^{2}$ of 0.90 . 
Now, given the relationship between SPC, SPP and SPX, we can test whether the found SPP loadings are driven by exposures to option returns, by replacing SPP with SPC. Table 9 shows the results of the factor model estimation. Comparing Table 3 with Table 9 shows that different indices have significant loadings on SPP and SPC, while the approximate put-call parity in returns suggests that the coefficients should be the same. Table 10 gives a side-by-side comparision of the coefficients for SPP and SPC in Tables 3 and 9 .

The three hedge fund indices for which the estimate of the loading on an option-based return factor is consistent are MA, EH and EM. For Equity Hedge (EH), the coefficient for the option factor is not significant in both models, so this rathers shows consistency in not loading on the option factor. For the Emerging Markets (EM) strategy the significant long-call exposure cannot be rejected based on the SPP loading, but we do not have a ready explanation for such an effect.

Finally, Merger Arbitrage (MA) is the strategy that has a significant negative exposure to the put return, and corresponding short call exposure, significant at the $90 \%$ level. This suggests that only Merger Arbitrage has resemblance to the return on a put option. Credibility to this claim is presented by Mitchell and Pulvino (2001).

\section{Portfolio sorts}

Although the results up to now do not suggest option-exposures are widespread, it is possible that many funds have such an exposure, but spread out over several style indices. To test for option exposures in individual hedge fund returns, we construct portfolios sorted directly on exposure to option returns. The data used is the individual fund database from TASS/CSFB, as described in Section 2. 
Creating the portfolio sorts is done as follows. For every month in the dataset, we select all funds with at least 18 months of historical returns and estimate a 5-factor model with factors SPX, SMB, HML, LHY and SPP (and a constant) using OLS. Then, we sort the funds based on the SPP-coefficient and create five asset-weighted portfolios, so that every portfolio contains $20 \%$ of the assets. The asset-weighted returns of each portfolio gives five portfolio returns for each month. Portfolio 1 contains funds with the lowest exposure to SPP, while portfolio 5 has funds with the highest exposure to SPP. The means and standard deviations of the five portfolios are in Table 11. From the table we observe that the mean and standard deviation are not continuously increasing or decreasing the in the portfolio number. We would expect the mean to be decreasing and the standard deviation to be increasing, given the properties of the SPP return in Table 1. In addition, Table 12 shows the factor regressions for the five portfolios. It shows the coefficient for SPP continuously increasing in the portfolio number, which verifies that our sorting procedure is working correctly. However, it also shows that the exposure to SPP is negative and significant for all but the 2nd quintile portfolio. So, maybe the short put exposure is there after all.

To test whether Table 12 is actually measuring exposure to SPP, we add a variable DVIX to the factor model. DVIX is the change in VIX (CBOE volatility index), and since option prices are positively related to volatility, the return to holding options should be negatively related to volatility. I.e., for a positive exposure to SPP, we expect to find a positive estimate for the DVIX, while for more negative exposures we expect a large negative sign for DVIX.

Table 13 lists the factor model with DVIX added, showing a significant positive exposure to DVIX for the third and fifth portfolio. This is not what we would expect, given the 
negative exposures to SPP. I.e., the returns to a short option position are negatively related to volatility. Hence, we cannot maintain that the loadings on SPP found in Table 12 represent actual exposure to put option returns.

Tables 14, 15 and 16 show the comparable results with SPP replaced by SPC, the call option return. Qualitatively, the results in Table 14 and 16 are identical to those with SPP: no continuous increasing or decreasing pattern in the means or standard deviation, and a positive relation with DVIX for two portfolios. A remarkable difference is in Table 15, where for portfolio 1, 2 and 5, the loadings on SPC are positive and significant.

\section{Conclusion}

Previous previous literature suggests that the returns on S\&P put-options explain a significant portion of hedge fund portfolio-returns. In this paper we have thoroughly put this claim to the test. Using both HFR and TASS supplied indices, two different sample periods, replacing put by call returns, and forming portfolios based on option loadings, our general findings cast significant doubt on the adequacy of put option returns for capturing part of the return variation in hedge fund indices. This is relevant for both risk management of hedge fund portfolios, as well as financial institutions that offer synthetic hedge fund indices. Our results suggest that models for hedge fund performance or replication should in general not include returns to equity index-options. 


\section{References}

Agarwal, V. and N. Naik (2004). Risks and Portfolio Decisions Involving Hedge Funds. Review of Financial Studies 17(1), 63-98.

Baquero, G. and M. Verbeek (2005). A Portrait of Hedge Fund Investors: Flows, Performance and Smart Money. RSM Erasmus University, Erasmus Research Institute of Management (ERIM).

Brown, S., D. Gallagher, O. Steenbeek, and P. Swan (2005). Double or Nothing: Patterns of Equity Fund Holdings and Transactions. Technical report, SSRN Working paper, http://ssrn. com/abstract $=555423$.

Chan, N., M. Getmansky, S. Haas, and A. Lo (2005). Systemic Risk and Hedge Funds. NBER Working Paper 11200.

Coval, J. and T. Shumway (2001). Expected Option Returns. The Journal of Finance 56(3), 983-1009.

de los Rios, A. and R. Garcia (2005). Assessing and Valuing the Nonlinear Structure of Hedge Funds Returns. Working paper, Universite de Montreal.

Fung, W. and D. Hsieh (2002). Asset-Based Style Factors for Hedge Funds. Financial Analysts Journal 58(5), 16-27.

Fung, W. and D. Hsieh (2004). Hedge fund benchmarks: A risk based approach. Financial Analysts Journal 60(5), 65-80.

Fung, W. and D. A. Hsieh (1997). Empirical characteristics of dynamic trading strategies: The case of hedge funds. Review of Financial Studies 10(2), 275-302.

Goetzmann, W., J. Ingersoll, M. Spiegel, and I. Welch (2002). Sharpening Sharpe Ratios. NBER working paper no. 9116.

Merton, R. (1981). On Market Timing and Investment Performance. I. An Equilibrium Theory of Value for Market Forecasts. The Journal of Business 54(3), 363-406.

Mitchell, M. and T. Pulvino (2001). Characteristics of Risk and Return in Risk Arbitrage. The Journal of Finance 56(6), 2135-2175.

Sharpe, W. F. (1992). Asset allocation: Management style and performance measurement. Journal of Portfolio Management 18, 7-19.

Siegmann, A. H. and A. Lucas (2007). The effect of shortfall as a risk measure for portfolios with hedge funds. Journal of Business, Finance, and Accounting forthcoming.

Weisman, A. (2002). Informationless Investing and Hedge Fund Performance Measurement Bias. The Journal of Portfolio Management 28, 80-91. 


\section{Appendix: Tables and Figures}

\section{Table 1: Hedge fund indices and market factors}

\begin{tabular}{ll} 
TASS & hedge fund indices \\
\hline CA & Convertible Arbitrage \\
DSB & Dedicated Short Bias \\
EM & Emerging Markets \\
EMN & Equity Market Neutral \\
ED & Event Driven \\
FI & Fixed Income Arbitrage \\
GM & Global Macro \\
LSE & Long-Short Equity \\
MF & Managed Futures \\
& \\
HFR hedge fund indices \\
\hline CA & Convertible Arbitrage \\
DS & Distressed Securities \\
ED & Event Driven \\
EH & Equity Hedge \\
EM & Emering Markets \\
EMN & Equity Market Neutral \\
ENH & Equity Non-Hedge \\
MA & Merger Arbitrage \\
Macro & Macro \\
RVA & Relative Value Arbitrage \\
SS & Short Selling \\
& \\
Market & Risk factors \\
\hline Rf & Risk-free rate, taken as the 90-day T-bill rate \\
SPX & Return on the S\&P 500 composite index \\
LHY & Lehman Brother Global High Yield index \\
SBG & World government and corporate bond index \\
SBW & World government bond index \\
MEM & MSCI emerging markets index \\
MXUS & MSCI excluding the US index \\
FRBI & Federal Reserve Bank competitiveness-weighted dollar index \\
DEF & change in the default spread (in basis points) \\
SPP & return on an at-the-money put option on the S\&P 500 \\
SPC & return on an at-the-money call option on the S\&P 500 \\
SMB & Fama-French size factor (small minus big) \\
HML & Fama-French book-to-market factor (high minus low) \\
GSCI & Goldman Sachs commodity index \\
&
\end{tabular}




\section{Table 2: Summary statistics}

This table shows the summary statistics for the HFR indices (panel A), TASS/Tremont indices (panel B), and the market indices (panel C).

\begin{tabular}{|c|c|c|c|c|c|c|c|}
\hline \multicolumn{8}{|c|}{ Panel A: HFR hedge fund indices } \\
\hline Hedge fund strategy & Mean & $\mathrm{SD}$ & Median & Skew & Kurt & Min & $\operatorname{Max}$ \\
\hline $\mathrm{CA}$ & 0.73 & 1.03 & 0.91 & -0.96 & 1.85 & -3.19 & 3.33 \\
\hline DS & 0.95 & 1.50 & 1.07 & -1.56 & 8.99 & -8.50 & 5.06 \\
\hline ED & 1.04 & 1.79 & 1.28 & -1.21 & 5.28 & -8.90 & 5.13 \\
\hline EH & 1.13 & 2.47 & 1.15 & 0.30 & 2.19 & -7.65 & 10.88 \\
\hline EM & 1.06 & 3.97 & 1.59 & -1.01 & 5.48 & -21.02 & 14.80 \\
\hline EMN & 0.63 & 0.86 & 0.57 & 0.29 & 1.02 & -1.67 & 3.59 \\
\hline ENH & 1.16 & 3.86 & 1.62 & -0.49 & 0.84 & -13.34 & 10.74 \\
\hline FI & 0.64 & 0.86 & 0.73 & -1.23 & 4.53 & -3.27 & 3.28 \\
\hline MA & 0.79 & 1.04 & 0.90 & -1.90 & 8.63 & -5.69 & 3.12 \\
\hline Macro & 0.82 & 2.00 & 0.72 & 0.07 & 1.16 & -6.40 & 6.82 \\
\hline MT & 0.96 & 2.13 & 0.98 & 0.16 & -0.18 & -4.41 & 6.43 \\
\hline RVA & 0.78 & 0.88 & 0.80 & -2.42 & 17.33 & -5.80 & 2.80 \\
\hline SS & 0.25 & 5.76 & -0.15 & 0.31 & 2.64 & -21.21 & 22.84 \\
\hline \multicolumn{8}{|c|}{ Panel B: TASS/Tremont hedge fund indices } \\
\hline Hedge fund strategy & Mean & SD & Median & Skew & Kurt & Min & $\operatorname{Max}$ \\
\hline $\mathrm{CA}$ & 0.71 & 1.32 & 1.02 & -1.31 & 3.18 & -4.68 & 3.57 \\
\hline DSB & -0.04 & 4.84 & -0.42 & 0.86 & 2.16 & -8.69 & 22.71 \\
\hline DS & 1.06 & 1.77 & 1.21 & -2.91 & 19.90 & -12.45 & 4.10 \\
\hline MS & 0.91 & 1.73 & 0.93 & -2.38 & 15.81 & -11.52 & 4.66 \\
\hline RA & 0.64 & 1.19 & 0.57 & -1.05 & 6.13 & -6.15 & 3.81 \\
\hline EM & 0.90 & 4.48 & 1.49 & -0.74 & 5.33 & -23.03 & 16.42 \\
\hline EMN & 0.80 & 0.81 & 0.79 & 0.34 & 0.55 & -1.15 & 3.26 \\
\hline ED & 0.95 & 1.59 & 1.06 & -3.32 & 23.98 & -11.77 & 3.68 \\
\hline FI & 0.51 & 1.05 & 0.72 & -2.98 & 16.12 & -6.96 & 2.05 \\
\hline GM & 1.13 & 3.00 & 1.17 & 0.02 & 3.53 & -11.55 & 10.60 \\
\hline LSE & 1.00 & 2.82 & 0.86 & 0.20 & 4.27 & -11.43 & 13.01 \\
\hline MF & 0.58 & 3.43 & 0.34 & 0.00 & 0.26 & -9.35 & 9.95 \\
\hline \multicolumn{8}{|c|}{ Panel C: Risk factors } \\
\hline Risk factor & Mean & $\mathrm{SD}$ & Median & Skew & Kurt & Min & Max \\
\hline$\overline{\mathrm{RF}}$ & 0.32 & 0.14 & 0.38 & -0.63 & -0.91 & 0.06 & 0.56 \\
\hline SPX & 0.92 & 4.02 & 1.36 & -0.61 & 0.92 & -14.46 & 9.78 \\
\hline HML & 0.33 & 3.48 & 0.33 & 0.09 & 3.10 & -12.80 & 13.80 \\
\hline SMB & 0.12 & 3.85 & -0.17 & 0.93 & 7.97 & -16.70 & 22.18 \\
\hline MEM & 0.91 & 6.45 & 1.05 & -0.83 & 2.14 & -28.91 & 13.77 \\
\hline LHY & 0.04 & 2.56 & 0.46 & -1.61 & 8.79 & -15.79 & 7.18 \\
\hline SBGC & 0.51 & 1.24 & 0.65 & -0.44 & 1.23 & -4.26 & 4.26 \\
\hline SBW & 0.52 & 1.85 & 0.29 & 0.32 & 0.31 & -4.28 & 5.94 \\
\hline MXUS & 0.78 & 4.01 & 0.88 & -0.52 & 0.62 & -12.75 & 10.44 \\
\hline FRBI & -0.12 & 1.75 & 0.01 & -0.07 & 0.01 & -4.46 & 4.44 \\
\hline DEF & 0.54 & 12.56 & -1.00 & 0.95 & 1.84 & -25.00 & 48.00 \\
\hline GSCI & 0.92 & 5.77 & 0.96 & 0.05 & 0.04 & -14.41 & 16.88 \\
\hline SPP & -0.26 & 0.79 & -0.58 & 1.62 & 2.68 & -0.98 & 3.39 \\
\hline SPC & -0.01 & 0.64 & -0.11 & 0.50 & -0.66 & -0.93 & 1.71 \\
\hline
\end{tabular}


Table 3: HFR index regressions 1994-2007

Factor model estimates for each of the HFR indices.

\begin{tabular}{|c|c|c|c|c|c|c|c|c|c|c|c|c|c|c|}
\hline & Const & SPX & HML & SMB & MEM & LHY & SBGC & SBW & MXUS & FRBI & DEF & GSCI & $\mathrm{SPP}$ & Adj. $R^{2}$ \\
\hline \multicolumn{15}{|c|}{ Non-directional } \\
\hline \multirow[t]{2}{*}{ ED } & $0.34^{* * *}$ & $0.15^{* * *}$ & $0.12^{* * *}$ & $0.22^{* * *}$ & 0.01 & $0.19^{* * *}$ & -0.03 & -0.02 & 0.01 & -0.03 & -0.01 & 0.01 & $-0.44 * * *$ & 0.78 \\
\hline & $(2.99)$ & $(2.86)$ & $(5.19)$ & $(10.47)$ & $(0.61)$ & ( 4.57$)$ & $(-0.34)$ & $(-0.19)$ & $(0.29)$ & $(-0.32)$ & $(-1.55)$ & $(0.92)$ & $(-2.37)$ & \\
\hline \multirow[t]{2}{*}{ RVA } & $0.26^{* * *}$ & 0.01 & $0.05^{* * *}$ & $0.05^{* * *}$ & -0.01 & $0.15^{* * *}$ & 0.00 & -0.06 & -0.02 & -0.06 & -0.01 & $0.02^{* * *}$ & $-0.34^{* *}$ & 0.48 \\
\hline & $(2.88)$ & $(0.38)$ & $(2.46)$ & $(3.21)$ & $(-0.83)$ & $(3.16)$ & $(0.06)$ & $(-0.99)$ & $(-0.60)$ & $(-1.06)$ & $(-1.43)$ & $(2.67)$ & $(-2.28)$ & \\
\hline \multirow[t]{2}{*}{$\mathrm{CA}$} & $0.31^{* * *}$ & -0.02 & 0.01 & 0.03 & -0.03 & $0.24^{* * *}$ & -0.01 & -0.06 & -0.02 & -0.09 & -0.00 & 0.01 & $-0.27^{*}$ & 0.30 \\
\hline & $(2.56)$ & $(-0.47)$ & $(0.44)$ & ( 1.58$)$ & $(-1.57)$ & $(5.10)$ & $(-0.10)$ & $(-0.73)$ & $(-0.38)$ & $(-1.06)$ & $(-0.19)$ & $(0.67)$ & $(-1.68)$ & \\
\hline \multirow[t]{2}{*}{ FI } & $0.33^{* * *}$ & 0.00 & 0.03 & $0.06^{* * *}$ & -0.00 & $0.14^{* * *}$ & 0.09 & -0.02 & 0.05 & 0.03 & $-0.01^{* * *}$ & $0.02^{*}$ & 0.03 & 0.48 \\
\hline & ( 3.33$)$ & $(0.01)$ & $(1.63)$ & $(4.40)$ & $(-0.05)$ & $(4.75)$ & $(1.44)$ & $(-0.26)$ & $(1.43)$ & $(0.45)$ & $(-3.36)$ & $(1.78)$ & $(0.18)$ & \\
\hline \multirow[t]{2}{*}{ MA } & 0.04 & 0.03 & $0.10^{* * *}$ & $0.10^{* * *}$ & -0.01 & $0.10^{* *}$ & $-0.13^{*}$ & -0.00 & -0.02 & -0.07 & 0.00 & 0.01 & $-0.67 * * *$ & 0.50 \\
\hline & $(0.34)$ & $(0.75)$ & $(5.43)$ & $(6.14)$ & $(-0.42)$ & $(2.02)$ & $(-1.83)$ & $(-0.05)$ & $(-0.71)$ & $(-1.05)$ & $(0.53)$ & $(1.28)$ & $(-3.68)$ & \\
\hline \multirow[t]{2}{*}{ EMN } & 0.09 & 0.02 & $0.06^{* * *}$ & $0.07^{* * *}$ & $-0.05^{* * *}$ & 0.01 & 0.11 & $-0.13^{*}$ & $0.06^{*}$ & $-0.13^{*}$ & 0.01 & 0.01 & -0.19 & 0.14 \\
\hline & $(0.84)$ & $(0.59)$ & $(2.35)$ & $(3.46)$ & $(-2.88)$ & $(0.26)$ & ( 1.38$)$ & $(-1.73)$ & $(1.84)$ & $(-1.77)$ & $(1.20)$ & $(1.29)$ & $(-1.08)$ & \\
\hline \multirow[t]{2}{*}{ DS } & $0.41^{* * *}$ & 0.01 & $0.10^{* * *}$ & $0.15^{* * *}$ & -0.00 & $0.23^{* * *}$ & -0.05 & 0.07 & 0.05 & 0.04 & $-0.02 *$ & 0.01 & $-0.39 *$ & 0.58 \\
\hline & $(2.91)$ & $(0.12)$ & $(2.84)$ & $(5.69)$ & $(-0.09)$ & $(4.16)$ & $(-0.46)$ & $(0.59)$ & $(0.70)$ & $(0.36)$ & $(-1.90)$ & $(0.37)$ & $(-1.75)$ & \\
\hline \multicolumn{15}{|l|}{ Directional } \\
\hline \multirow[t]{2}{*}{ Macro } & -0.00 & -0.10 & 0.02 & $0.12^{* * *}$ & $0.11^{* * *}$ & -0.02 & $0.49^{* * *}$ & 0.19 & 0.09 & $0.35^{* *}$ & 0.00 & $0.05^{* * *}$ & $-0.71^{*}$ & 0.45 \\
\hline & $(-0.01)$ & $(-1.01)$ & $(0.52)$ & ( 3.28$)$ & $(3.70)$ & $(-0.23)$ & ( 3.44$)$ & ( 1.14$)$ & ( 1.44$)$ & $(2.13)$ & $(0.05)$ & $(2.53)$ & $(-1.86)$ & \\
\hline \multirow[t]{2}{*}{ ENH } & 0.19 & $0.58 * * *$ & -0.06 & $0.45 * * *$ & $0.08 * * *$ & 0.02 & 0.00 & -0.02 & 0.02 & -0.12 & -0.00 & $0.03^{* *}$ & -0.25 & 0.92 \\
\hline & ( 1.33$)$ & $(7.11)$ & $(-1.62)$ & (13.48) & ( 3.29$)$ & $(0.46)$ & $(0.00)$ & $(-0.15)$ & $(0.32)$ & $(-1.09)$ & $(-0.03)$ & $(2.10)$ & $(-0.93)$ & \\
\hline \multirow[t]{2}{*}{$\mathrm{EH}$} & $0.32^{*}$ & $0.28^{* * *}$ & -0.04 & $0.29 * * *$ & 0.03 & -0.02 & 0.10 & -0.12 & 0.06 & -0.09 & 0.01 & $0.05^{* * *}$ & -0.29 & 0.79 \\
\hline & ( 1.78$)$ & $(3.82)$ & $(-1.00)$ & (9.66) & ( 1.07$)$ & $(-0.40)$ & $(0.88)$ & $(-1.02)$ & $(1.42)$ & $(-0.79)$ & $(0.83)$ & ( 3.29$)$ & $(-1.03)$ & \\
\hline \multirow[t]{2}{*}{ SS } & 0.29 & $-0.84^{* * *}$ & $0.46^{* * *}$ & $-0.60^{* * *}$ & 0.03 & -0.05 & -0.02 & -0.10 & -0.04 & -0.04 & -0.00 & -0.03 & -0.13 & 0.80 \\
\hline & $(0.92)$ & $(-5.57)$ & ( 6.06$)$ & $(-9.74)$ & $(0.57)$ & $(-0.43)$ & $(-0.08)$ & $(-0.30)$ & $(-0.38)$ & $(-0.14)$ & $(-0.18)$ & $(-0.94)$ & $(-0.20)$ & \\
\hline \multirow[t]{2}{*}{ EM } & $0.67^{* * *}$ & -0.04 & -0.00 & 0.06 & $0.48^{* * *}$ & $0.20^{* * *}$ & $0.36^{* *}$ & $-0.40^{* *}$ & 0.08 & -0.11 & -0.02 & 0.02 & 0.36 & 0.81 \\
\hline & $(2.66)$ & $(-0.28)$ & $(-0.02)$ & $(1.52)$ & (11.20) & $(2.44)$ & ( 2.07$)$ & $(-2.28)$ & $(0.65)$ & $(-0.69)$ & $(-0.91)$ & $(0.82)$ & $(0.92)$ & \\
\hline \multirow[t]{2}{*}{ MT } & 0.11 & $0.17^{* * *}$ & -0.04 & $0.11 * * *$ & $0.09 * * *$ & $-0.25 * * *$ & $0.46^{* * *}$ & $-0.35^{* *}$ & $0.15^{* *}$ & -0.24 & 0.01 & 0.02 & -0.14 & 0.61 \\
\hline & $(0.56)$ & ( 2.53$)$ & $(-0.89)$ & ( 2.77$)$ & ( 2.75$)$ & $(-2.65)$ & ( 3.18$)$ & $(-2.00)$ & ( 2.12$)$ & $(-1.45)$ & $(0.51)$ & $(1.22)$ & $(-0.48)$ & \\
\hline
\end{tabular}


Table 4: HFR index regressions 1994-2000

Factor model estimates for each of the HFR indices.

\begin{tabular}{|c|c|c|c|c|c|c|c|c|c|c|c|c|c|c|}
\hline & Const & SPX & HML & SMB & MEM & LHY & SBGC & SBW & MXUS & FRBI & DEF & GSCI & SPP & Adj. $R^{2}$ \\
\hline \multicolumn{15}{|l|}{ Non-directional } \\
\hline \multirow[t]{2}{*}{$\mathrm{ED}$} & $0.64^{* * *}$ & $0.28^{* * *}$ & $0.21^{* * *}$ & $0.28^{* * *}$ & 0.01 & $0.18^{* * *}$ & -0.02 & -0.08 & -0.01 & -0.03 & $-0.03^{* * *}$ & 0.01 & -0.13 & 0.79 \\
\hline & $(3.59)$ & $(4.55)$ & $(6.01)$ & $(9.64)$ & $(0.23)$ & $(3.84)$ & $(-0.17)$ & $(-0.42)$ & $(-0.17)$ & $(-0.16)$ & $(-3.06)$ & $(0.55)$ & $(-0.58)$ & \\
\hline \multirow[t]{2}{*}{ RVA } & $0.32^{* *}$ & $0.15^{* * *}$ & $0.15^{* * *}$ & $0.13^{* * *}$ & $-0.06^{* * *}$ & $0.20^{* * *}$ & -0.14 & -0.10 & -0.03 & -0.05 & $-0.02^{*}$ & $0.03^{* * *}$ & -0.26 & 0.69 \\
\hline & $(2.24)$ & $(2.91)$ & $(5.06)$ & $(8.57)$ & $(-3.11)$ & $(5.04)$ & $(-1.25)$ & $(-1.02)$ & $(-1.02)$ & $(-0.58)$ & $(-1.92)$ & $(2.41)$ & $(-1.20)$ & \\
\hline \multirow[t]{2}{*}{$\mathrm{CA}$} & $0.45^{* * *}$ & -0.01 & $0.07 *$ & $0.07^{* * *}$ & -0.02 & $0.25^{* * *}$ & -0.06 & -0.01 & 0.00 & 0.03 & 0.00 & -0.00 & -0.34 & 0.42 \\
\hline & $(2.47)$ & $(-0.13)$ & ( 1.78$)$ & $(3.16)$ & $(-1.02)$ & $(3.03)$ & $(-0.40)$ & $(-0.06)$ & $(0.08)$ & $(0.22)$ & $(0.06)$ & $(-0.09)$ & $(-1.28)$ & \\
\hline \multirow[t]{2}{*}{ FI } & $0.35^{* *}$ & 0.02 & $0.07^{* * *}$ & $0.09^{* * *}$ & -0.00 & $0.10^{* * *}$ & $0.18^{*}$ & -0.11 & $0.06^{*}$ & 0.04 & $-0.03^{* * *}$ & 0.00 & 0.02 & 0.48 \\
\hline & (1.99) & $(0.35)$ & (3.08) & $(5.28)$ & $(-0.15)$ & $(2.39)$ & $(1.76)$ & $(-0.72)$ & $(1.95)$ & $(0.40)$ & $(-4.30)$ & $(0.12)$ & $(0.08)$ & \\
\hline \multirow[t]{2}{*}{ MA } & $0.35^{* *}$ & $0.10^{* *}$ & $0.13^{* * *}$ & $0.12^{* * *}$ & -0.02 & $0.17^{* * *}$ & $-0.28 * * *$ & -0.06 & $-0.07^{* *}$ & -0.16 & -0.00 & 0.00 & $-0.52^{* *}$ & 0.53 \\
\hline & $(2.09)$ & $(2.05)$ & $(3.64)$ & $(5.33)$ & $(-0.93)$ & $(2.60)$ & $(-2.44)$ & $(-0.48)$ & $(-2.26)$ & $(-1.24)$ & $(-0.30)$ & $(0.00)$ & $(-2.27)$ & \\
\hline \multirow[t]{2}{*}{ EMN } & 0.22 & $0.12^{* *}$ & 0.05 & $0.09^{* * *}$ & $-0.09 * * *$ & 0.08 & 0.01 & -0.14 & 0.06 & -0.14 & 0.00 & 0.01 & -0.05 & 0.18 \\
\hline & $(1.16)$ & $(2.00)$ & $(1.19)$ & $(2.71)$ & $(-3.29)$ & $(1.37)$ & $(0.10)$ & $(-0.91)$ & $(1.60)$ & $(-0.99)$ & $(0.51)$ & $(0.38)$ & $(-0.18)$ & \\
\hline \multirow[t]{2}{*}{ DS } & 0.10 & 0.08 & $0.23^{* * *}$ & $0.24^{* * *}$ & -0.03 & $0.21^{* * *}$ & -0.13 & -0.12 & 0.07 & $\begin{array}{l}-0.02 \\
\end{array}$ & -0.02 & 0.01 & $-0.69^{* *}$ & 0.74 \\
\hline & $(0.45)$ & $(1.10)$ & $(5.93)$ & $(8.01)$ & $(-0.92)$ & $(4.23)$ & $(-0.96)$ & $(-0.66)$ & $(1.21)$ & $(-0.15)$ & $(-1.39)$ & $(0.39)$ & $(-2.31)$ & \\
\hline \multicolumn{15}{|l|}{ Directional } \\
\hline \multirow[t]{2}{*}{ Macro } & 0.30 & 0.04 & 0.03 & $0.17^{* * *}$ & $0.10^{* *}$ & -0.04 & $0.59^{* * *}$ & 0.24 & $0.13^{*}$ & $0.76^{* * *}$ & -0.01 & 0.02 & -0.35 & 0.56 \\
\hline & $(0.68)$ & $0.31)$ & $(0.42)$ & $(3.59)$ & $(2.28)$ & $(-0.39)$ & $(2.61)$ & $(0.77)$ & $(1.93)$ & $(2.62)$ & $(-0.49)$ & $(0.71)$ & $(-0.54)$ & \\
\hline \multirow[t]{2}{*}{ ENH } & 0.26 & $0.76^{* * *}$ & -0.01 & $0.54^{* * *}$ & 0.04 & -0.03 & $-0.46^{* *}$ & $0.38^{*}$ & -0.00 & 0.27 & -0.01 & 0.01 & -0.19 & 0.90 \\
\hline & $(0.87)$ & $(6.61)$ & $(-0.19)$ & (12.92) & ( 1.02$)$ & $(-0.26)$ & $(-2.05)$ & $(1.73)$ & $(-0.08)$ & $(1.39)$ & $(-0.39)$ & $(0.32)$ & $(-0.43)$ & \\
\hline \multirow[t]{2}{*}{$\mathrm{EH}$} & $0.90^{* * *}$ & $0.52^{* * *}$ & -0.02 & $0.38^{* * *}$ & 0.02 & -0.05 & -0.13 & 0.08 & 0.04 & 0.16 & 0.00 & $0.05 *$ & 0.30 & 0.81 \\
\hline & $(3.08)$ & $(4.89)$ & $(-0.36)$ & (9.13) & $(0.47)$ & $(-0.57)$ & $(-0.65)$ & $(0.40)$ & $(0.91)$ & $(0.87)$ & $(0.13)$ & $(1.73)$ & $(0.71)$ & \\
\hline \multirow[t]{2}{*}{ SS } & 0.84 & $-0.86^{* * *}$ & $0.54^{* * *}$ & $-0.75^{* * *}$ & -0.04 & 0.09 & 0.85 & $-1.50^{* *}$ & -0.01 & $-1.14^{*}$ & -0.00 & 0.08 & 0.65 & 0.82 \\
\hline & $(1.59)$ & $(-3.63)$ & $(4.43)$ & $(-8.41)$ & $(-0.52)$ & $(0.47)$ & $(1.37)$ & $(-2.03)$ & $(-0.05)$ & $(-1.87)$ & $(-0.11)$ & $(1.37)$ & $(0.68)$ & \\
\hline \multirow[t]{2}{*}{ EM } & $1.09^{* * *}$ & 0.24 & 0.17 & $0.20^{* * *}$ & $0.50^{* * *}$ & $0.20^{*}$ & 0.34 & $-0.57^{*}$ & 0.07 & -0.12 & -0.05 & 0.03 & $1.08^{*}$ & 0.82 \\
\hline & $(2.68)$ & $(1.24)$ & $(1.64)$ & $(2.91)$ & $(8.05)$ & ( 1.89$)$ & $(0.92)$ & $(-1.76)$ & $(0.53)$ & $(-0.50)$ & $(-1.25)$ & $(0.55)$ & $(1.76)$ & \\
\hline \multirow[t]{2}{*}{ MT } & $0.86^{* * *}$ & $0.33^{* * *}$ & $-0.16^{* * *}$ & 0.07 * & 0.06 & $-0.22^{* *}$ & 0.32 & -0.06 & $0.19^{* *}$ & 0.19 & 0.03 & 0.01 & $0.91^{* *}$ & 0.59 \\
\hline & ( 2.58$)$ & ( 3.28$)$ & $(-3.03)$ & $(1.72)$ & $(1.52)$ & $(-1.98)$ & ( 1.49$)$ & $(-0.27)$ & $(2.12)$ & $(0.93)$ & $(1.61)$ & $(0.38)$ & $(1.97)$ & \\
\hline
\end{tabular}


Table 5: HFR index regressions 2000-2007

Factor model estimates for each of the HFR indices.

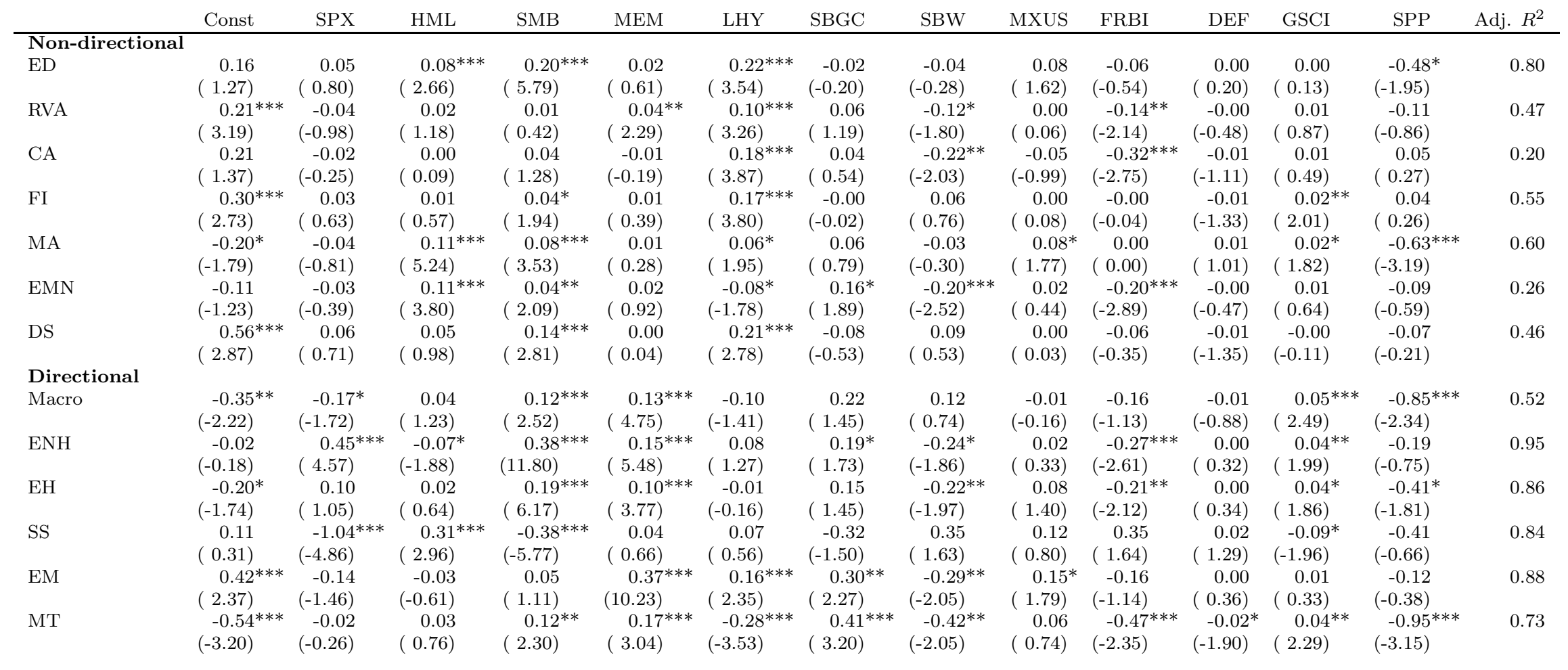


Table 6: TASS/CSFB index regressions 1994-2007

Factor model estimates for each of the TASS/CSFB, currently Hedgeindex indices.

\begin{tabular}{|c|c|c|c|c|c|c|c|c|c|c|c|c|c|c|}
\hline & Const & SPX & HML & SMB & MEM & LHY & SBGC & SBW & MXUS & FRBI & DEF & GSCI & SPP & Adj. $R^{2}$ \\
\hline \multicolumn{15}{|c|}{ Non-directional } \\
\hline \multirow[t]{2}{*}{ CA } & $0.30^{*}$ & -0.05 & $0.06^{*}$ & $0.05^{*}$ & $-0.05^{* *}$ & $0.30 * * *$ & -0.02 & -0.16 & 0.00 & -0.12 & -0.00 & 0.01 & -0.30 & 0.24 \\
\hline & $\begin{array}{l}(1.83) \\
0.44 * * *\end{array}$ & $\begin{array}{r}(-0.62) \\
-0.02\end{array}$ & $\begin{array}{l}(1.83) \\
0.07 *\end{array}$ & $\begin{array}{l}(1.75) \\
0.09 * * *\end{array}$ & $\begin{array}{r}(-1.98) \\
-0.01\end{array}$ & $\begin{array}{l}(5.68) \\
0.34 * * *\end{array}$ & $\begin{array}{r}(-0.15) \\
-0.05\end{array}$ & $\begin{array}{r}(-1.44) \\
0.01\end{array}$ & $\begin{array}{r}(0.04) \\
0.05\end{array}$ & $\begin{array}{r}(-1.23) \\
0.03\end{array}$ & $\begin{array}{l}(-0.08) \\
-0.02 *\end{array}$ & $\begin{array}{r}(0.93) \\
0.02\end{array}$ & $\begin{array}{l}(-1.31) \\
-0.62^{* *}\end{array}$ & 060 \\
\hline DS & $(2.70)$ & $(-0.25)$ & $(1.96)$ & $(2.60)$ & $(-0.28)$ & $(3.96)$ & $(-0.44)$ & $(0.11)$ & $(0.91)$ & $(0.26)$ & $(-1.95)$ & $(1.31)$ & $\begin{array}{l}-0.02 \\
(-2.20)\end{array}$ & 0.60 \\
\hline \multirow[t]{2}{*}{ EMN } & $0.42^{* * *}$ & 0.06 & 0.01 & 0.00 & 0.01 & 0.03 & -0.04 & 0.06 & -0.00 & 0.02 & 0.00 & 0.01 & -0.02 & 0.11 \\
\hline & $(4.33)$ & ( 1.36$)$ & $(0.47)$ & $(0.04)$ & $(0.58)$ & ( 0.89$)$ & $(-0.43)$ & $(0.64)$ & $(-0.00)$ & $(0.23)$ & ( 1.08$)$ & $(1.20)$ & $(-0.13)$ & \\
\hline \multirow[t]{2}{*}{ FI } & 0.09 & -0.12 & 0.03 & 0.00 & -0.02 & $0.17^{* * *}$ & 0.08 & -0.08 & 0.04 & -0.00 & -0.01 & $0.02^{* *}$ & -0.33 & 0.15 \\
\hline & $(0.53)$ & $(-1.57)$ & ( 1.11$)$ & $(0.13)$ & $(-0.75)$ & $(3.57)$ & $(0.77)$ & $(-0.67)$ & $(0.70)$ & $(-0.02)$ & $(-1.50)$ & $(2.19)$ & $(-1.38)$ & \\
\hline \multirow[t]{2}{*}{ ED } & $0.38^{* * *}$ & -0.01 & $0.08^{* * *}$ & $0.09^{* * *}$ & 0.02 & $0.26^{* * *}$ & -0.01 & -0.12 & 0.07 & -0.04 & -0.01 & $0.02^{*}$ & -0.41 & 0.63 \\
\hline & $(2.62)$ & $(-0.12)$ & $(2.84)$ & ( 3.78$)$ & $(0.82)$ & $(3.06)$ & $(-0.07)$ & $(-1.08)$ & $(1.15)$ & $(-0.47)$ & $(-1.14)$ & $(1.82)$ & $(-1.59)$ & \\
\hline \multirow[t]{2}{*}{$\mathrm{RA}$} & 0.11 & 0.07 & $0.10^{* * *}$ & $0.11^{* * *}$ & 0.02 & 0.08 & -0.13 & 0.04 & 0.00 & -0.04 & 0.00 & -0.00 & -0.20 & 0.38 \\
\hline & $(0.80)$ & ( 1.31$)$ & $(3.37)$ & $(3.81)$ & ( 1.04$)$ & ( 1.37$)$ & $(-1.53)$ & $(0.42)$ & $(0.06)$ & $(-0.39)$ & $(0.63)$ & $(-0.09)$ & $(-0.92)$ & \\
\hline \multicolumn{15}{|l|}{ Directional } \\
\hline \multirow[t]{2}{*}{$\mathrm{EM}$} & $0.68 * *$ & -0.20 & -0.08 & -0.00 & $0.47^{* * *}$ & $0.35^{* * *}$ & $0.58^{* *}$ & $-0.63^{* *}$ & 0.14 & -0.11 & -0.02 & 0.01 & 0.38 & 0.66 \\
\hline & $(1.96)$ & $(-1.14)$ & $(-1.14)$ & $(-0.08)$ & $(6.64)$ & $(2.51)$ & $(2.19)$ & $(-2.04)$ & $(0.81)$ & $(-0.40)$ & $(-0.93)$ & $(0.38)$ & $(0.68)$ & \\
\hline \multirow[t]{2}{*}{ GM } & 0.35 & -0.09 & 0.08 & 0.08 & 0.08 & 0.05 & $0.63^{* *}$ & 0.20 & 0.07 & $0.77^{* * *}$ & -0.01 & 0.05 & -0.97 & 0.22 \\
\hline & ( 0.93$)$ & $(-0.54)$ & ( 0.99$)$ & $(1.26)$ & $(1.20)$ & $(0.45)$ & $(2.10)$ & $(0.57)$ & $(0.50)$ & $(2.64)$ & $(-0.54)$ & $(1.52)$ & $(-1.57)$ & \\
\hline \multirow[t]{2}{*}{ MS } & $0.42^{* * *}$ & 0.00 & $0.08^{* * *}$ & $0.10^{* * *}$ & 0.04 & $0.21^{* * *}$ & 0.06 & -0.26 & 0.08 & -0.11 & -0.01 & $0.03^{*}$ & -0.18 & 0.52 \\
\hline & $(2.41)$ & $(0.03)$ & $(2.44)$ & $(3.32)$ & ( 1.13$)$ & $(2.39)$ & $(0.49)$ & $(-1.61)$ & $(1.06)$ & $(-0.81)$ & $(-0.57)$ & $(1.76)$ & $(-0.60)$ & \\
\hline \multirow[t]{2}{*}{ LSE } & 0.12 & 0.13 & $-0.14^{* *}$ & $0.26^{* * *}$ & 0.03 & 0.06 & $0.38^{* *}$ & -0.21 & $0.12^{*}$ & -0.15 & 0.01 & $0.05^{* *}$ & -0.52 & 0.66 \\
\hline & $(0.47)$ & $(1.21)$ & $(-2.12)$ & $(5.73)$ & ( 0.68$)$ & $(0.65)$ & $(2.15)$ & $(-1.23)$ & $(1.85)$ & $(-0.91)$ & $(0.96)$ & $(2.32)$ & $(-1.25)$ & \\
\hline \multirow[t]{2}{*}{ DSB } & 0.36 & $-0.76^{* * *}$ & 0.13 & $-0.40^{* * *}$ & -0.00 & $-0.24^{* *}$ & 0.20 & -0.02 & 0.12 & 0.25 & 0.01 & -0.01 & 0.52 & 0.75 \\
\hline & $(1.00)$ & $(-5.11)$ & $(1.57)$ & $(-5.40)$ & $(-0.10)$ & $(-2.16)$ & $(0.80)$ & $(-0.07)$ & $(1.30)$ & $(0.98)$ & $(0.36)$ & $(-0.20)$ & $(0.91)$ & \\
\hline \multirow[t]{2}{*}{ MF } & -0.47 & -0.22 & 0.14 & 0.05 & $0.15^{*}$ & $-0.42^{* * *}$ & 0.58 & 0.33 & 0.10 & 0.08 & 0.00 & $0.07^{*}$ & -0.62 & 0.12 \\
\hline & $(-1.00)$ & $(-1.14)$ & ( 1.43$)$ & $(0.62)$ & ( 1.94$)$ & $(-2.36)$ & ( 1.42$)$ & $(0.67)$ & $(0.63)$ & $(0.19)$ & $(0.14)$ & $(1.66)$ & $(-0.76)$ & \\
\hline
\end{tabular}


Table 7: TASS/CSFB index regressions, 1994-2000

Factor model estimates for each of the TASS/CSFB, currently Hedgeindex indices, from Jan. 1994 to Jun. 2000. (78 months)

\begin{tabular}{|c|c|c|c|c|c|c|c|c|c|c|c|c|c|c|}
\hline & Const & SPX & HML & SMB & MEM & LHY & SBGC & SBW & MXUS & FRBI & $\mathrm{DEF}$ & GSCI & SPP & Adj. $R^{2}$ \\
\hline \multicolumn{15}{|c|}{ Non-directional } \\
\hline \multirow[t]{2}{*}{$\mathrm{CA}$} & $0.59^{* * *}$ & -0.01 & $0.16^{* * *}$ & $0.10^{* * *}$ & $-0.07^{*}$ & $0.36^{* * *}$ & -0.09 & -0.19 & 0.04 & 0.02 & 0.01 & 0.03 & -0.13 & 0.33 \\
\hline & $(2.36)$ & $(-0.10)$ & $(2.80)$ & ( 2.93$)$ & $(-1.72)$ & ( 4.89$)$ & $(-0.42)$ & $(-0.8$ & $(0.64)$ & $(0.15)$ & $(0.28)$ & $(1.21)$ & $(-0.31)$ & \\
\hline \multirow[t]{2}{*}{ DS } & 0.27 & 0.06 & $0.17^{* * *}$ & $0.13^{* * *}$ & -0.02 & $0.37 * * *$ & -0.06 & -0.08 & 0.05 & -0.13 & $-0.04 * * *$ & 0.02 & $-0.81^{* *}$ & 0.71 \\
\hline & $(1.12)$ & $(0.77)$ & $(2.90)$ & $(2.94)$ & $(-0.52)$ & $(5.03)$ & $(-0.32)$ & $(-0.33)$ & $(0.68)$ & $(-0.63)$ & $(-2.73)$ & ( 1.05$)$ & $(-2.27)$ & \\
\hline \multirow[t]{2}{*}{ EMN } & $0.56^{* * *}$ & $0.22^{* * *}$ & $0.07^{* *}$ & $0.06^{* *}$ & -0.01 & 0.01 & -0.20 & 0.07 & 0.02 & 0.10 & 0.01 & 0.03 & 0.32 & 0.17 \\
\hline & $(3.45)$ & $(3.54)$ & $(2.23)$ & $(2.30)$ & $(-0.33)$ & $(0.26)$ & $(-0.97)$ & $(0.31)$ & $(0.41)$ & $(0.54)$ & $(1.30)$ & $(1.43)$ & $(1.17)$ & \\
\hline \multirow[t]{2}{*}{ FI } & 0.04 & -0.12 & 0.06 & 0.02 & -0.03 & $0.21^{* * *}$ & 0.14 & -0.28 & 0.03 & 0.01 & -0.01 & 0.01 & -0.50 & 0.25 \\
\hline & $(0.16)$ & $(-1.28)$ & ( 1.31$)$ & $(0.81)$ & $(-0.75)$ & $(2.52)$ & $(1.00)$ & $(-1.41)$ & $(0.42)$ & $(0.05)$ & $(-0.92)$ & $(0.57)$ & $(-1.32)$ & \\
\hline \multirow[t]{2}{*}{ ED } & $0.40^{*}$ & $0.16^{* *}$ & $0.19^{* * *}$ & $0.17^{* * *}$ & -0.02 & $0.31^{* * *}$ & 0.02 & $-0.33^{* *}$ & 0.06 & -0.19 & $-0.04 * * *$ & 0.02 & -0.25 & 0.77 \\
\hline & $(1.91)$ & $(2.17)$ & $(4.60)$ & $(5.31)$ & $(-0.61)$ & $4.59)$ & $(0.14)$ & $(-2.02)$ & $(1.14)$ & $(-1.26)$ & $(-2.47)$ & $(0.93)$ & $(-0.81)$ & \\
\hline \multirow[t]{2}{*}{$\mathrm{RA}$} & 0.29 & $0.16^{* *}$ & $0.15^{* * *}$ & $0.18^{* * *}$ & 0.01 & 0.13 & $-0.37^{* *}$ & 0.09 & -0.03 & 0.02 & -0.00 & -0.03 & -0.20 & 0.39 \\
\hline & ( 1.13$)$ & ( 1.98$)$ & ( 2.49$)$ & $(3.52)$ & $(0.18)$ & $(1.51)$ & $(-2.17)$ & $(0.45)$ & $(-0.60)$ & $(0.11)$ & $(-0.17)$ & $(-0.95)$ & $(-0.58)$ & \\
\hline \multicolumn{15}{|c|}{ Directional } \\
\hline \multirow[t]{2}{*}{ EM } & $1.87^{* * *}$ & 0.11 & 0.15 & $0.16^{*}$ & $0.51^{* * *}$ & $0.55^{* * *}$ & $0.99 *$ & $-1.27^{* *}$ & 0.19 & -0.56 & -0.08 & -0.03 & $1.95^{* *}$ & 0.72 \\
\hline & $(2.92)$ & $(0.40)$ & $(0.08)$ & $170)$ & $(4.69)$ & $(2.59)$ & $(1.72)$ & $(-2.13)$ & $(0.98)$ & $(-0.99)$ & $(-1.46)$ & $(-0.38)$ & $(2.01)$ & \\
\hline \multirow[t]{2}{*}{ GM } & -0.10 & 0.10 & 0.08 & $0.21^{* *}$ & 0.05 & -0.13 & 0.42 & 0.73 & 0.08 & $1.89 * * *$ & -0.04 & 0.04 & -1.37 & 0.36 \\
\hline & $(-0.13)$ & $(0.41)$ & $(0.54)$ & $(2.20)$ & $(0.48)$ & $(-0.60)$ & $(0.70)$ & $(0.84)$ & $(0.55)$ & $(2.86)$ & $(-1.00)$ & $(0.51)$ & $(-1.23)$ & \\
\hline \multirow[t]{2}{*}{ MS } & $0.64^{* * *}$ & $0.26^{* * *}$ & $0.22^{* * *}$ & $0.21^{* * *}$ & -0.03 & $0.28^{* * *}$ & 0.14 & $-0.64 * * *$ & 0.10 & -0.25 & -0.03 & 0.03 & 0.38 & 0.68 \\
\hline & $(2.42)$ & $(2.72)$ & $(4.24)$ & $(5.24)$ & $(-0.52)$ & $(3.41)$ & $(0.72)$ & $(-2.96)$ & $(1.30)$ & $(-1.27)$ & $(-1.43)$ & $(0.95)$ & $(0.96)$ & \\
\hline \multirow[t]{2}{*}{ LSE } & 0.41 & $0.47^{* * *}$ & $-0.24^{* * *}$ & $0.35^{* * *}$ & 0.04 & -0.03 & 0.32 & -0.09 & 0.06 & 0.15 & -0.01 & 0.03 & 0.11 & 0.82 \\
\hline & $(1.00)$ & ( 3.73$)$ & $(-2.55)$ & $(5.64)$ & $(0.75)$ & $(-0.27)$ & $(1.34)$ & $(-0.38)$ & $(0.95)$ & $(0.64)$ & $(-0.80)$ & $(0.91)$ & $(0.20)$ & \\
\hline \multirow[t]{2}{*}{ DSB } & $0.79^{*}$ & $-1.12^{* * *}$ & 0.11 & $-0.48 * * *$ & 0.08 & -0.21 & $1.27 * * *$ & -0.24 & 0.06 & -0.18 & -0.05 & -0.02 & 0.33 & 0.79 \\
\hline & $(1.72)$ & $(-5.80)$ & $(0.97)$ & $(-6.68)$ & $(1.00)$ & $(-1.47)$ & ( 3.17$)$ & $(-0.48)$ & $(0.48)$ & $(-0.46)$ & $(-1.28)$ & $(-0.35)$ & $(0.47)$ & \\
\hline \multirow[t]{2}{*}{ MF } & $1.22^{* * *}$ & 0.22 & 0.03 & -0.03 & 0.14 & $-0.44^{* * *}$ & 0.39 & 0.63 & $0.27^{*}$ & 0.67 & 0.03 & 0.11 & $2.37 * * *$ & 0.11 \\
\hline & $(2.47)$ & $(1.00)$ & $(0.28)$ & $(-0.36)$ & $(1.47)$ & $(-2.77)$ & $(0.54)$ & $(0.74)$ & $(1.71)$ & ( 1.07$)$ & $(0.61)$ & $(1.55)$ & $(2.59)$ & \\
\hline
\end{tabular}


Table 8: TASS/CSFB index regressions, 2000-2004

Factor model estimates for each of the TASS/CSFB, currently Hedgeindex indices, for the period Jul. 2000 - Dec. 2004.

\begin{tabular}{|c|c|c|c|c|c|c|c|c|c|c|c|c|c|c|}
\hline & Const & SPX & HML & SMB & MEM & LHY & SBGC & SBW & MXUS & FRBI & $\mathrm{DEF}$ & GSCI & SPP & Adj. $R^{2}$ \\
\hline \multicolumn{15}{|l|}{ Non-directional } \\
\hline \multirow[t]{2}{*}{$\mathrm{CA}$} & 0.18 & -0.00 & 0.03 & $0.08^{*}$ & -0.03 & $0.22^{* * *}$ & 0.01 & $-0.24^{*}$ & -0.06 & $-0.39 * * *$ & -0.01 & 0.00 & -0.09 & 0.19 \\
\hline & $(1.02)$ & $(-0.02)$ & $(0.68)$ & ( 1.92$)$ & $(-1.11)$ & ( 3.90$)$ & $(0.11)$ & $(-1.88)$ & $(-0.94)$ & $(-2.74)$ & $(-0.56)$ & $(0.18)$ & $(-0.42)$ & \\
\hline \multirow[t]{2}{*}{ DS } & $0.56^{* * *}$ & -0.06 & 0.04 & $0.13^{* * *}$ & -0.02 & $0.25^{* * *}$ & 0.03 & -0.16 & 0.10 & -0.08 & -0.01 & 0.00 & -0.21 & 0.52 \\
\hline & $(3.30)$ & $(-0.82)$ & $(0.80)$ & $(2.66)$ & $(-0.56)$ & $(3.00)$ & $(0.23)$ & $(-1.04)$ & $(1.35)$ & $(-0.61)$ & $(-1.26)$ & $(0.26)$ & $(-0.70)$ & \\
\hline \multirow[t]{2}{*}{ EMN } & $0.27^{* * *}$ & -0.05 & -0.00 & -0.03 & 0.03 & 0.03 & -0.05 & 0.03 & -0.00 & -0.06 & -0.00 & 0.00 & -0.17 & 0.09 \\
\hline & $(3.70)$ & $(-1.35)$ & $(-0.14)$ & $(-1.51)$ & $(1.45)$ & $(1.00)$ & $(-0.74)$ & $(0.41)$ & $(-0.10)$ & $(-0.93)$ & $(-0.07)$ & $(0.29)$ & $(-1.30)$ & \\
\hline \multirow[t]{2}{*}{ FI } & 0.08 & -0.09 & 0.01 & 0.01 & -0.04 & $0.10^{* *}$ & -0.00 & -0.02 & 0.05 & -0.14 & -0.01 & $0.02^{* *}$ & -0.17 & 0.15 \\
\hline & $(0.43)$ & $(-1.28)$ & $(0.40)$ & $(0.25)$ & $(-1.04)$ & $(2.02)$ & $(-0.01)$ & $(-0.22)$ & $(0.89)$ & $(-1.30)$ & $(-1.56)$ & $(2.20)$ & $(-0.69)$ & \\
\hline \multirow[t]{2}{*}{ ED } & $0.34^{* *}$ & -0.07 & 0.05 & $0.08^{* * *}$ & 0.04 & $0.18^{* * *}$ & -0.05 & -0.09 & 0.07 & -0.10 & 0.00 & 0.01 & -0.34 & 0.56 \\
\hline & $(2.28)$ & $(-1.11)$ & $(1.32)$ & ( 2.37$)$ & $(1.14)$ & $(2.73)$ & $(-0.49)$ & $(-0.59)$ & ( 1.17$)$ & $(-0.81)$ & $(0.10)$ & $(0.95)$ & $(-1.25)$ & \\
\hline \multirow[t]{2}{*}{ RA } & -0.08 & 0.07 & $0.11^{* * *}$ & $0.08^{* *}$ & 0.04 & 0.03 & 0.04 & 0.00 & 0.03 & -0.07 & 0.01 & 0.01 & -0.09 & 0.49 \\
\hline & $(-0.66)$ & $(1.43)$ & $(3.95)$ & $(2.13)$ & $(1.47)$ & $(0.72)$ & $(0.58)$ & $(0.04)$ & $(0.61)$ & $(-0.58)$ & $(1.21)$ & $(0.77)$ & $(-0.44)$ & \\
\hline \multicolumn{15}{|l|}{ Directional } \\
\hline \multirow[t]{2}{*}{ EM } & 0.02 & -0.15 & -0.02 & -0.00 & $0.35^{* * *}$ & 0.07 & $0.37^{* * *}$ & -0.14 & 0.01 & -0.04 & -0.01 & 0.03 & $-0.66^{*}$ & 0.78 \\
\hline & $(0.13)$ & $(-1.42)$ & $(-0.43)$ & $(-0.04)$ & $(8.67)$ & $(0.92)$ & $(2.35)$ & $(-0.83)$ & $(0.13)$ & $(-0.26)$ & $(-0.49)$ & ( 1.48$)$ & $(-1.87)$ & \\
\hline \multirow[t]{2}{*}{ GM } & $0.36^{* *}$ & -0.12 & 0.08 & 0.02 & $0.11^{* * *}$ & -0.03 & $0.25^{*}$ & -0.14 & -0.08 & $-0.24^{*}$ & -0.01 & 0.02 & -0.46 & 0.20 \\
\hline & ( 1.99$)$ & $(-1.15)$ & ( 1.62$)$ & ( 0.49$)$ & $(2.71)$ & $(-0.45)$ & $(1.85)$ & $(-1.02)$ & $(-0.91)$ & $(-1.87)$ & $(-1.01)$ & ( 1.17$)$ & $(-1.29)$ & \\
\hline \multirow[t]{2}{*}{ MS } & 0.21 & -0.08 & 0.06 & 0.05 & $0.07^{*}$ & $0.15^{* *}$ & -0.12 & -0.05 & 0.04 & -0.13 & 0.01 & 0.02 & -0.47 & 0.49 \\
\hline & ( 1.18$)$ & $(-1.20)$ & ( 1.32$)$ & ( 1.42$)$ & ( 1.93$)$ & ( 2.27$)$ & $(-0.93)$ & $(-0.26)$ & $(0.57)$ & $(-0.76)$ & $(0.87)$ & ( 1.18$)$ & $(-1.56)$ & \\
\hline \multirow[t]{2}{*}{ LSE } & $-0.41^{* * *}$ & -0.13 & 0.02 & $0.08^{* *}$ & 0.04 & 0.01 & 0.11 & -0.12 & $0.18^{* *}$ & $-0.29 *$ & 0.01 & 0.03 & $-1.06^{* * *}$ & 0.67 \\
\hline & $(-3.06)$ & $(-1.27)$ & $(0.32)$ & ( 2.18$)$ & $(1.22)$ & ( 0.19$)$ & $(0.82)$ & $(-0.88)$ & ( 2.23$)$ & $(-1.92)$ & $(0.80)$ & ( 1.10$)$ & $(-4.45)$ & \\
\hline \multirow[t]{2}{*}{ DSB } & 0.60 & $-0.60 * * *$ & 0.14 & $-0.43^{* * *}$ & 0.03 & -0.17 & -0.09 & 0.08 & 0.17 & 0.47 & 0.03 & -0.03 & $1.24^{*}$ & 0.73 \\
\hline & ( 1.43$)$ & $(-3.07)$ & $(1.22)$ & $(-4.00)$ & $(0.44)$ & $(-0.99)$ & $(-0.33)$ & $(0.20)$ & ( 1.05$)$ & ( 1.45$)$ & ( 1.54$)$ & $(-0.71)$ & ( 1.67$)$ & \\
\hline \multirow[t]{2}{*}{ MF } & $-1.76^{* * *}$ & $-0.60^{* *}$ & 0.16 & $0.26^{*}$ & 0.07 & -0.33 & 0.43 & 0.49 & -0.10 & -0.08 & -0.02 & $0.12^{* *}$ & $-3.51^{* * *}$ & 0.22 \\
\hline & $(-3.09)$ & $(-2.05)$ & $(1.27)$ & ( 1.93$)$ & $(0.59)$ & $(-1.38)$ & $(0.98)$ & $(0.81)$ & $(-0.33)$ & $(-0.14)$ & $(-0.60)$ & ( 2.11) & $(-3.40)$ & \\
\hline
\end{tabular}


Table 9: HFR index regressions with call option factor

Factor model estimates for each of the HFR indices, with the call option factor.

\begin{tabular}{|c|c|c|c|c|c|c|c|c|c|c|c|c|c|c|}
\hline & Const & SPX & HML & SMB & MEM & LHY & SBGC & SBW & MXUS & FRBI & DEF & GSCI & SPC & Adj. $R^{2}$ \\
\hline \multicolumn{15}{|l|}{ Non-directional } \\
\hline \multirow[t]{2}{*}{ ED } & $0.70^{* * *}$ & $0.17 * * *$ & $0.11^{* * *}$ & $0.22^{* * *}$ & 0.01 & $0.20^{* * *}$ & 0.02 & -0.11 & 0.02 & -0.08 & -0.01 & 0.01 & $0.37^{*}$ & 0.77 \\
\hline & $(5.53)$ & ( 2.89$)$ & ( 4.71) & (9.93) & $(0.46)$ & $(4.27)$ & $(0.22)$ & $(-1.00)$ & $(0.43)$ & $(-0.83)$ & $(-1.51)$ & ( 1.04$)$ & ( 1.68$)$ & \\
\hline \multirow[t]{2}{*}{ RVA } & $0.44^{* * *}$ & 0.07 & $0.05^{* * *}$ & $0.06^{* * *}$ & -0.01 & $0.15^{* * *}$ & 0.04 & -0.11 & -0.01 & -0.08 & -0.01 & $0.02^{* * *}$ & 0.04 & 0.46 \\
\hline & ( 3.78$)$ & $(1.34)$ & ( 2.33$)$ & ( 3.39$)$ & $(-0.87)$ & ( 3.20$)$ & $(0.54)$ & $(-1.45)$ & $(-0.44)$ & $(-1.22)$ & $(-1.41)$ & $(2.73)$ & ( 0.19$)$ & \\
\hline \multirow[t]{2}{*}{$\mathrm{CA}$} & $0.64^{* * *}$ & -0.05 & 0.00 & 0.03 & $-0.03^{*}$ & $0.25^{* * *}$ & 0.02 & -0.15 & -0.01 & -0.14 & -0.00 & 0.01 & $0.47^{* *}$ & 0.31 \\
\hline & $(5.24)$ & $(-0.85)$ & $(0.13)$ & $(1.46)$ & $(-1.74)$ & $(5.41)$ & $(0.29)$ & $(-1.54)$ & $(-0.33)$ & $(-1.61)$ & $(-0.16)$ & $(0.74)$ & $(2.17)$ & \\
\hline \multirow[t]{2}{*}{ FI } & $0.52^{* * *}$ & -0.08 & 0.02 & $0.05^{* * *}$ & -0.00 & $0.15^{* * *}$ & 0.09 & -0.08 & $0.05^{*}$ & -0.02 & $-0.01^{* * *}$ & $0.01 *$ & 0.47 & 0.51 \\
\hline & ( 4.06$)$ & $(-1.24)$ & ( 1.15$)$ & ( 4.35$)$ & $(-0.26)$ & ( 4.43$)$ & ( 1.42$)$ & $(-0.77)$ & ( 1.67$)$ & $(-0.25)$ & $(-3.45)$ & ( 1.79$)$ & ( 1.60$)$ & \\
\hline \multirow[t]{2}{*}{ MA } & 0.17 & $0.21 * * *$ & $0.11 * * *$ & $0.11^{* * *}$ & -0.00 & $0.09 *$ & -0.07 & -0.02 & -0.01 & -0.05 & 0.00 & 0.02 & $-0.43^{*}$ & 0.47 \\
\hline & $(1.42)$ & $(4.50)$ & ( 5.35$)$ & $(6.42)$ & $(-0.26)$ & ( 1.85$)$ & $(-0.93)$ & $(-0.26)$ & $(-0.41)$ & $(-0.68)$ & $(0.45)$ & ( 1.53$)$ & $(-1.85)$ & \\
\hline \multirow[t]{2}{*}{ EMN } & $0.25^{*}$ & 0.03 & $0.06^{* *}$ & $0.07^{* * *}$ & $-0.05^{* * *}$ & 0.02 & $0.13^{*}$ & $-0.17 * *$ & $0.06^{*}$ & $-0.15^{* *}$ & 0.01 & 0.02 & 0.16 & 0.14 \\
\hline & ( 1.87$)$ & ( 0.69$)$ & $(2.27)$ & ( 3.49$)$ & $(-2.97)$ & $(0.35)$ & ( 1.68$)$ & $(-2.23)$ & ( 1.93$)$ & $(-2.08)$ & ( 1.21$)$ & ( 1.37$)$ & ( 0.69$)$ & \\
\hline \multirow[t]{2}{*}{ DS } & $0.90^{* * *}$ & -0.04 & $0.09^{* * *}$ & $0.15^{* * *}$ & -0.01 & $0.25^{* * *}$ & -0.01 & -0.06 & 0.05 & -0.04 & $-0.02 *$ & 0.01 & $0.73^{* *}$ & 0.59 \\
\hline & $(5.60)$ & $(-0.42)$ & ( 2.49$)$ & $(5.25)$ & $(-0.32)$ & ( 3.88$)$ & $(-0.06)$ & $(-0.48)$ & $(0.85)$ & $(-0.41)$ & $(-1.87)$ & $(0.47)$ & ( 2.12$)$ & \\
\hline \multicolumn{15}{|l|}{ Directional } \\
\hline \multirow[t]{2}{*}{ Macro } & $0.95^{* * *}$ & $-0.20^{* * *}$ & -0.01 & $0.11^{* * *}$ & $0.10^{* * *}$ & 0.02 & $0.57^{* * *}$ & -0.07 & $0.10^{*}$ & 0.18 & 0.00 & $0.05^{* * *}$ & $1.47^{* * *}$ & 0.48 \\
\hline & ( 4.49) & $(-2.48)$ & $(-0.12)$ & ( 3.09$)$ & ( 3.51$)$ & ( 0.38$)$ & ( 4.08$)$ & $(-0.43)$ & ( 1.92$)$ & ( 1.13$)$ & ( 0.13$)$ & ( 2.87$)$ & ( 4.07$)$ & \\
\hline \multirow[t]{2}{*}{ ENH } & $0.64^{* * *}$ & $0.50^{* * *}$ & $-0.07 * *$ & $0.45^{* * *}$ & $0.07^{* * *}$ & 0.05 & 0.03 & -0.14 & 0.02 & $-0.20^{*}$ & 0.00 & $0.03^{* *}$ & $0.78^{* * *}$ & 0.92 \\
\hline & ( 4.69$)$ & $(7.27)$ & $(-2.11)$ & (13.31) & (3.00) & ( 0.98$)$ & $(0.26)$ & $(-1.01)$ & $(0.43)$ & $(-1.74)$ & $(0.02)$ & $(2.23)$ & ( 2.78$)$ & \\
\hline \multirow[t]{2}{*}{$\mathrm{EH}$} & $0.54^{* * *}$ & $0.30^{* * *}$ & -0.05 & $0.30^{* * *}$ & 0.03 & -0.01 & 0.13 & -0.17 & 0.06 & -0.11 & 0.01 & $0.05^{* * *}$ & 0.19 & 0.78 \\
\hline & $(3.56)$ & $(4.74)$ & $(-1.08)$ & ( 9.34$)$ & ( 1.00$)$ & $(-0.29)$ & ( 1.15$)$ & $(-1.39)$ & ( 1.52$)$ & $(-0.98)$ & $(0.84)$ & ( 3.39$)$ & ( 0.69$)$ & \\
\hline \multirow[t]{2}{*}{ SS } & -0.24 & $-0.61^{* * *}$ & $0.49^{* * *}$ & $-0.58^{* * *}$ & 0.04 & -0.08 & -0.02 & 0.05 & -0.04 & 0.08 & -0.00 & -0.03 & $-1.38^{* * *}$ & 0.81 \\
\hline & $(-0.85)$ & $(-5.46)$ & ( 6.74$)$ & $(-9.85)$ & $(0.76)$ & $(-0.80)$ & $(-0.08)$ & $(0.16)$ & $(-0.39)$ & $(0.28)$ & $(-0.21)$ & $(-0.95)$ & $(-2.44)$ & \\
\hline EM & $0.92^{* * *}$ & $-0.26^{*}$ & -0.02 & $\begin{array}{r}0.05 \\
(19)\end{array}$ & $0.47^{* * *}$ & $0.23^{* * *}$ & $0.33 *$ & $-0.49 * * *$ & 0.08 & -0.19 & -0.02 & $\begin{array}{r}0.02 \\
(075)\end{array}$ & $1.00^{* *}$ & 0.82 \\
\hline \multirow[t]{2}{*}{ MT } & $0.77^{* * *}$ & $\begin{array}{r}(-1.74) \\
-0.02\end{array}$ & $\begin{array}{r}(-0.40) \\
-0.06\end{array}$ & $0.10^{* * *}$ & $\begin{array}{l}(11.30) \\
0.08^{* * *}\end{array}$ & $\begin{array}{l}(2.59) \\
-0.21 * * *\end{array}$ & $\begin{array}{c}1.91) \\
0.48^{* * *}\end{array}$ & $\begin{array}{l}(-2.40) \\
\quad-0.54^{* * *}\end{array}$ & $\begin{array}{l}(0.66) \\
0.15^{* * *}\end{array}$ & $\begin{array}{l}(-1.22) \\
-0.38^{* *}\end{array}$ & $\begin{array}{r}(-0.88) \\
0.01\end{array}$ & 0.02 & $\begin{array}{l}1.97) \\
1.39^{* * *}\end{array}$ & 0.65 \\
\hline & ( 4.09) & $(-0.19)$ & $(-1.58)$ & ( 2.48$)$ & $(2.54)$ & $(-2.93)$ & ( 3.67$)$ & $(-2.90)$ & ( 2.59$)$ & $(-2.19)$ & $(0.60)$ & $(1.20)$ & $(3.44)$ & \\
\hline
\end{tabular}




\section{Table 10: Comparison of SPP and SPC for HFR indices}

This table shows the regression estimates for the HFR indices with SPX and SPP (columns 2-4) compared to a model with SPX and SPC (columns 5-7). Both models are estimated with all 12 factors, as in Table

3. The last two columns give the difference in OLS estimate, and a T-statistic for the hypothesis that the parameters are the same.

$$
\text { Model with SPP Model with SPC }
$$

\begin{tabular}{lrrr|rrrrr} 
& Const & SPX & SPP & Const & SPX & SPC & diff & tval \\
\hline ED & 0.34 & 0.15 & -0.44 & 0.70 & 0.17 & 0.37 & 0.80 & 4.37 \\
RVA & 0.26 & 0.01 & -0.34 & 0.44 & 0.07 & 0.04 & 0.38 & 2.59 \\
CA & 0.31 & -0.02 & -0.27 & 0.64 & -0.05 & 0.47 & 0.75 & 4.59 \\
FI & 0.33 & 0.00 & 0.03 & 0.52 & -0.08 & 0.47 & 0.45 & 2.87 \\
MA & 0.04 & 0.03 & -0.67 & 0.17 & 0.21 & -0.43 & 0.24 & 1.30 \\
EMN & 0.09 & 0.02 & -0.19 & 0.25 & 0.03 & 0.16 & 0.35 & 1.97 \\
DS & 0.41 & 0.01 & -0.39 & 0.90 & -0.04 & 0.73 & 1.12 & 5.00 \\
Macro & -0.00 & -0.10 & -0.71 & 0.95 & -0.20 & 1.47 & 2.19 & 5.70 \\
ENH & 0.19 & 0.58 & -0.25 & 0.64 & 0.50 & 0.78 & 1.03 & 3.80 \\
EH & 0.32 & 0.28 & -0.29 & 0.54 & 0.30 & 0.19 & 0.49 & 1.70 \\
SS & 0.29 & -0.84 & -0.13 & -0.24 & -0.61 & -1.38 & -1.25 & -2.05 \\
EM & 0.67 & -0.04 & 0.36 & 0.92 & -0.26 & 1.00 & 0.64 & 1.61 \\
MT & 0.11 & 0.17 & -0.14 & 0.77 & -0.02 & 1.39 & 1.53 & 5.10
\end{tabular}




\section{Table 11: SPP-sorted portfolios}

Mean and standard variation of the sorted portfolios. The SPP sorts are from a 5 factor model (SPX, SMB, MEM, LHY, SPP). Funds belonging to styles DSB and FoF, or not reporting in USD are discarded. Period is $1994-2004$.

\begin{tabular}{lrrrrr}
\hline SPP beta & 1 & 2 & 3 & 4 & 5 \\
\hline Mean & 0.35 & 0.80 & 0.67 & 0.57 & 0.46 \\
Stdev & 3.70 & 2.80 & 1.96 & 1.57 & 2.26 \\
\hline
\end{tabular}

Table 12: Factor estimates of SPP-sorted portfolios, with SPP

Sorted on 5 factors

\begin{tabular}{rrrcrccr} 
& Const & SPX & SMB & MEM & LHY & SPP & Adj. $R^{2}$ \\
\hline 1 & -0.39 & -0.18 & 0.08 & 0.08 & $0.34^{* *}$ & $-1.60^{* *}$ & 0.27 \\
& $(-0.89)$ & $(-0.95)$ & $(1.05)$ & $(0.87)$ & $(2.20)$ & $(-2.14)$ & \\
2 & 0.21 & -0.03 & $0.16^{* * *}$ & 0.00 & 0.15 & $-1.13^{*}$ & 0.25 \\
& $(0.73)$ & $(-0.22)$ & $(2.53)$ & $(0.00)$ & $(1.20)$ & $(-1.85)$ & \\
3 & 0.11 & -0.08 & $0.10^{* * *}$ & 0.04 & $0.15^{* *}$ & $-1.13^{* * *}$ & 0.50 \\
& $(0.40)$ & $(-0.88)$ & $(2.80)$ & $(1.12)$ & $(2.01)$ & $(-2.50)$ & \\
4 & 0.20 & -0.04 & $0.08^{* * *}$ & 0.04 & $0.10^{*}$ & $-0.73^{* * *}$ & 0.42 \\
& $(1.08)$ & $(-0.55)$ & $(3.26)$ & $(1.21)$ & $(1.74)$ & $(-2.81)$ & \\
5 & 0.03 & 0.06 & $0.15^{* * *}$ & 0.06 & 0.04 & $-0.70^{* * *}$ & 0.46 \\
& $(0.13)$ & $(0.73)$ & $(4.76)$ & $(1.51)$ & $(0.69)$ & $(-2.37)$ &
\end{tabular}

Table 13: Factor estimates of SPP-sorted portfolios, with DVIX

Sorted on 5 factors

\begin{tabular}{ccccrccr} 
& Const & SPX & SMB & MEM & LHY & DVIX & Adj. $R^{2}$ \\
\hline 1 & 0.24 & 0.16 & 0.11 & 0.08 & $0.40^{* *}$ & 0.09 & 0.25 \\
& $(0.83)$ & $(1.33)$ & $(1.30)$ & $(0.90)$ & $(2.20)$ & $(0.57)$ & \\
2 & $0.62^{* * *}$ & $0.26^{* * *}$ & $0.19^{* * *}$ & 0.01 & $0.23^{*}$ & $0.19^{*}$ & 0.26 \\
& $(2.91)$ & $(3.14)$ & $(2.87)$ & $(0.10)$ & $(1.89)$ & $(1.87)$ & \\
3 & $0.54^{* * *}$ & $0.18^{* * *}$ & $0.13^{* * *}$ & 0.04 & $0.21^{* * *}$ & $0.11^{* *}$ & 0.47 \\
& $(4.12)$ & $(3.50)$ & $(3.03)$ & $(1.24)$ & $(2.38)$ & $(2.05)$ & \\
4 & $0.47^{* * *}$ & $0.14^{* * *}$ & $0.10^{* * *}$ & 0.04 & $0.14^{* *}$ & $0.09^{*}$ & 0.42 \\
& $(4.12)$ & $(3.38)$ & $(3.43)$ & $(1.21)$ & $(2.21)$ & $(1.79)$ & \\
5 & $0.27^{* *}$ & $0.27^{* * *}$ & $0.17^{* * *}$ & 0.07 & $0.11^{*}$ & $0.17^{* * *}$ & 0.49 \\
& $(2.02)$ & $(4.23)$ & $(4.99)$ & $(1.54)$ & $(1.90)$ & $(2.46)$ &
\end{tabular}




\section{Table 14: SPC-sorted portfolios}

Mean and standard variation of the sorted portfolios. The SPC sorts are from a 5 factor model (SPX, SMB, MEM, LHY, SPP). Funds belonging to styles DSB and FoF, or not reporting in USD are discarded. Period is $1994-2004$.

\begin{tabular}{lrrrrr}
\hline SPC beta & 1 & 2 & 3 & 4 & 5 \\
\hline Mean & 0.98 & 0.72 & 0.55 & 0.51 & 0.08 \\
Stdev & 2.80 & 2.14 & 2.02 & 2.50 & 2.99 \\
\hline
\end{tabular}

Table 15: Factor estimates of SPC-sorted portfolios, with SPC

Sorted on 5 factors

\begin{tabular}{rlrcrccr} 
& Const & SPX & SMB & MEM & LHY & SPC & Adj. $R^{2}$ \\
\hline 1 & $1.44^{* * *}$ & 0.03 & $0.09^{*}$ & -0.02 & $0.21^{* *}$ & $1.58^{* *}$ & 0.28 \\
& $(4.06)$ & $(0.33)$ & $(1.74)$ & $(-0.36)$ & $(1.98)$ & $(2.26)$ & \\
2 & $1.06^{* * *}$ & -0.05 & 0.07 & 0.03 & $0.24^{* * *}$ & $1.11^{* *}$ & 0.34 \\
& $(3.85)$ & $(-0.50)$ & $(1.60)$ & $(0.77)$ & $(2.57)$ & $(2.04)$ & \\
3 & $0.58^{* * *}$ & 0.03 & $0.11^{* *}$ & $0.07^{*}$ & $0.18^{* *}$ & 0.28 & 0.39 \\
& $(2.64)$ & $(0.28)$ & $(2.29)$ & $(1.76)$ & $(2.04)$ & $(0.49)$ & \\
4 & $0.68^{* * *}$ & -0.00 & $0.23^{* * *}$ & 0.02 & $0.21^{*}$ & 0.72 & 0.36 \\
& $(3.28)$ & $(-0.03)$ & $(3.59)$ & $(0.34)$ & $(1.86)$ & $(1.05)$ & \\
5 & $0.92^{* * *}$ & -0.22 & $0.20^{* * *}$ & 0.10 & 0.18 & $2.60^{* * *}$ & 0.45 \\
& $(3.73)$ & $(-1.61)$ & $(3.88)$ & $(1.56)$ & $(1.29)$ & $(3.29)$ &
\end{tabular}

Table 16: Factor estimates of SPC-sorted portfolios, with DVIX

Sorted on 5 factors

\begin{tabular}{cccccccc} 
& Const & SPX & SMB & MEM & LHY & DVIX & Adj. $R^{2}$ \\
\hline 1 & $0.79^{* * *}$ & $0.36^{* * *}$ & $0.09^{*}$ & -0.01 & $0.24^{* * *}$ & $0.21^{* * *}$ & 0.29 \\
& $(4.16)$ & $(3.84)$ & $(1.72)$ & $(-0.19)$ & $(2.35)$ & $(2.45)$ & \\
2 & $0.61^{* * *}$ & $0.17^{* * *}$ & 0.07 & 0.03 & $0.26^{* * *}$ & $0.11^{* *}$ & 0.33 \\
& $(4.19)$ & $(3.00)$ & $(1.55)$ & $(0.87)$ & $(2.89)$ & $(2.02)$ & \\
3 & $0.47^{* * *}$ & $0.09^{*}$ & $0.11^{* *}$ & $0.07^{*}$ & $0.19^{* *}$ & 0.04 & 0.39 \\
& $(3.48)$ & $(1.66)$ & $(2.26)$ & $(1.83)$ & $(2.21)$ & $(0.59)$ & \\
4 & $0.39^{* *}$ & $0.13^{*}$ & $0.23^{* * *}$ & 0.03 & $0.21^{*}$ & 0.05 & 0.35 \\
& $(2.09)$ & $(1.69)$ & $(3.53)$ & $(0.37)$ & $(1.86)$ & $(0.48)$ & \\
5 & -0.13 & $0.27^{* * *}$ & $0.19^{* * *}$ & $0.11^{*}$ & 0.21 & $0.25^{*}$ & 0.41 \\
& $(-0.55)$ & $(3.53)$ & $(3.63)$ & $(1.89)$ & $(1.31)$ & $(1.80)$ &
\end{tabular}




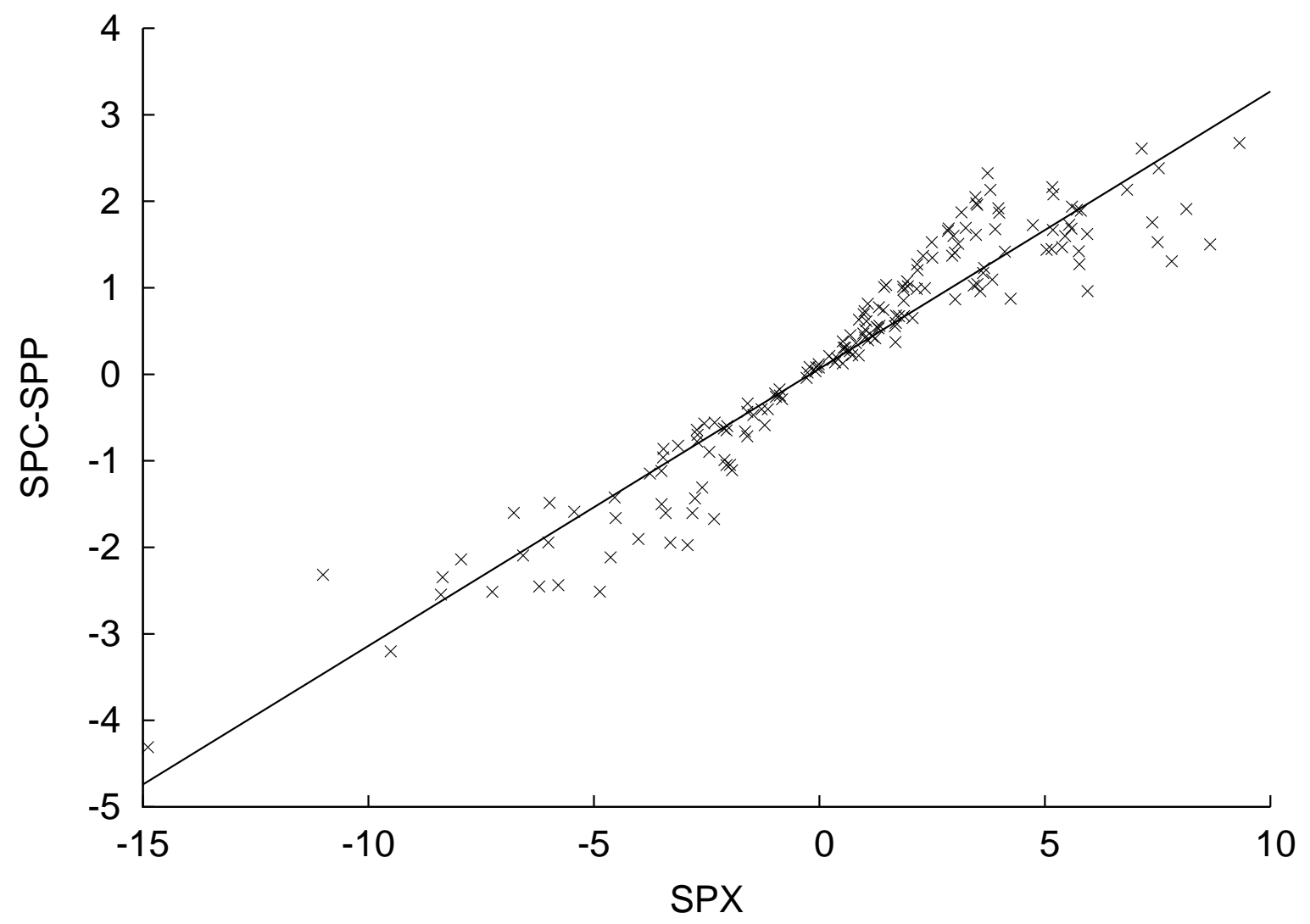

Figure 1: Collinearity of the option factors with the SPX return.

A scatterplot of SPC minus SPP against the S\&P 500 returns (SPX). The straight line represents the fitted OLS estimate, $y=0.07+0.32 \cdot x$, with an $R^{2}$ of 0.90 . 